\title{
CORRESPONDENCE
}

\section{FDA not NIH can speed new drugs}

Finding ways to accelerate the development of new pharmaceuticals is a worthy goal, but delegating the task to the US National Institutes of Health (NIH) is a bad idea

(Nature 471, 135; 2011).

Change is needed at the US

Food and Drug Administration (FDA), not the NIH.

The NIH has long excelled at funding and conducting basic research, but it should leave the development of commercial products to the private sector. Expenditures on commercial enterprises are likely to reduce the funding available for basic research.

Government bureaucrats are rarely leaders of technological innovation. They are not qualified to act as venture capitalists in choosing the most promising and deserving commercial product to fund and develop.

NIH director Francis Collins is right to be frustrated at how many basic science discoveries with therapeutic potential are waiting for follow-up by the pharmaceutical industry (G. Harris, The New York Times, 22 January 2011). But his colleagues at the FDA bear much of the responsibility for drug companies' reluctance or inability to take these forward.

Drug approvals have been dismal at a time when drug development should have been spurred by spending and new technologies. Expenditure on research and development by US-based drug companies almost quadrupled to more than US\$65 billion between 1995 and 2009.

Fred Hassan, former chief executive of drug company Schering-Plough, asked "What will it take to get new drugs approved? The point is, we don't know." Kenneth
Kaitin, director of the Tufts Center for the Study of Drug Development, blamed the FDA's 'obstructionist' culture for its reputation as "an agency that is supposed to keep unsafe drugs off the market, not to speed access to lifesaving drugs" (The Wall Street Journal, 30 June 2008).

Henry I. Miller Hoover Institution, Stanford University, USA.

henry.miller@stanford.edu

\section{Libyan uprising may boost bluefin tuna}

The unrest in the Middle East could provide an unexpected shield for endangered stocks of bluefin tuna (Thunnus thynnus) around the Libyan coast.

From 2002, fishing operations off Libya have been highly lucrative. Vessels often catch tuna worth $€ 500,000$ (about US\$712,000) in a single haul. The Libyan government banned foreign tuna fishing in its exclusive economic zone from 2004. But the French tuna-fishing fleet negotiated Libyan licences for some of its vessels, and immediately resumed fishing for Mediterranean bluefins.

Then came the Libyan revolution and the military intervention by France and its allies. The French tunafishing fleet is likely to lose its access to Libyan waters for the foreseeable future. This is good news for tuna. Like North Atlantic fish stocks during the First and Second World Wars, Mediterranean bluefins are likely to escape trawlers as long as military operations are under way. Such a fishing curfew could be more effective than decades of recommendations by the International Commission for the Conservation of Atlantic Tunas. A similar situation effectively stopped tuna fishing in the western Indian Ocean from 2007 - as a result of Somalian piracy.

David Grémillet Centre for Functional and Evolutionary Ecology, CNRS, UMR5175, Montpellier, France; and PFIAO, DST/NRF Centre of Excellence, University of Cape Town, South Africa.david.gremillet@cefe.cnrs.fr Amélie Lescroël University of Rennes and the National Museum of Natural History, UMR7204, Rennes, France.

\section{Predicting the threat of nuclear disasters}

The failures at Japan's Fukushima Daiichi nuclear power plant after the tsunami on 11 March have led people to question the risks associated with nuclear power stations. But disasters on this scale can be considered to be very unlikely if it is assumed, like natural catastrophes, that the more energy that is required to cause an event, the less likely it is to happen.

In the biosphere, for example, extinctions of single species or communities of organisms occur much more frequently than mass extinctions. Such natural events show a logarithmic scale of frequency distribution when plotted against energy input.

Soon after the Chernobyl disaster, Kenneth Hsü suggested that man-made accidents might show a similar frequencymagnitude relationship (Nature 328, 22; 1987). He proposed that financial costs could be used as a measure of magnitude, because every small accident has a monetary equivalent - for example, in lost electricitysupply payments and insuranceclaim payouts. Everything from the smallest mishaps (such as temporary shutdowns) to the largest catastrophes could thus provide a wide range of data points, putting statistical assessment of nuclear-accident probabilities on a firmer footing than, say, radiation-leak measurements (Nature 335, 391; 1988). It may be time to take a fresh look at Hsü's proposals for gauging the safety of nuclear power plants.

A. M. Celâl Şengör Istanbul Technical University, Turkey. sengor@itu.edu.tr

\section{Regional drought has a global impact}

In today's interconnected world, regional droughts can have a global impact on food supplies and undermine the economics and stability of governments.

For example, droughts last year in Russia and Ukraine reduced the wheat harvest by $32.7 \%$ and $19.3 \%$, respectively, severely diminishing the worldwide wheat supply. China, the world's largest wheat producer and consumer, is being forced to import grain after a continuing drought in its northern growing region (Nature 470, 307; 2011).

The fall in wheat production has contributed to a sharp rise in global prices - by February 2011, these had more than doubled in 8 months. The economies of wheat-importing countries in the Middle East and North Africa are particularly hard hit. This is especially true of Egypt, the world's largest wheat importer, and Tunisia and Libya, where the steep rise in the cost of food is fuelling political and economic dissatisfaction.

Troy Sternberg University of Oxford, UK.

troy.sternberg@geog.ox.ac.uk

\section{CONTRIBUTIONS}

Correspondence may be sent to correspondence@ nature.com after consulting the author guidelines at go.nature.com/cmchno 